\title{
Natural Ageing Tests to Study In-service Different Façade Solutions-ETICS and Premixed One-Coat Rendered Walls
}

\author{
Luís Silva $^{1}$, Inês Flores-Colen ${ }^{2}$, Nuno Vieira ${ }^{1}$ and Ana Barros Timmons ${ }^{3}$ \\ 1. Saint Gobain Weber Portugal, Aveiro 3800-055, Portugal \\ 2. Instituto Superior Técnico, Department of Civil Engineering and Architecture, University of Lisbon, Lisboa 1049-001, Portugal \\ 3. CICECO (Centre for Research in Ceramics and Composite Materials)-Aveiro Institute of Materials, Department of Chemistry, \\ University of Aveiro, Aveiro 3910-183, Portugal
}

\begin{abstract}
In situ testing provides accurate characterization of existing degradation mechanisms of materials and building systems which helps reducing the subjectivity of visual inspections especially when ageing under natural ageing conditions is carried out over significant periods of time. In this work, data collected from field experimental campaigns over 10 years after construction using several premixed one-coat rendered walls and over 4 and 6 years after construction in the case of ETICS (external thermal insulation composite systems) are presented and discussed. The influence of hydrophobic agents on the performance of both types of façades in terms of surface condition and water penetration was assessed by visual inspections, Karsten test and capillary tests. Additionally, adhesion tests and subsequent evaluation of porosity were also carried out for premixed one-coat mortars. The results obtained have shown that ageing of the rendering solutions, especially after 5 or 6 years in-service, results from the loss of resistance to liquid water penetration, especially at the surface. Yet, additional mechanisms such as leaching of hydrophobic agents and photochemical degradation are thought to be involved, too. Moreover, the results obtained using the Karsten test proved to be the most reliable method to determine the loss of water penetration resistance and predict the ageing of façade solutions. The information collected and the correlations established can help developing solutions to prevent early ageing and implement appropriate maintenance plans to delay their effect.
\end{abstract}

Key words: Natural ageing tests, façade solutions, water resistance, hydrophobic agents, adhesion.

\section{Introduction}

Aesthetics, waterproofing and, nowadays, thermal insulation are the main functions that a façade's cladding must fulfill during its service life. The observation of façades over time of exposure to environmental conditions suggests that aesthetic is strongly conditioned by the performance that a cladding system has in the presence of water and its effective capacity to prevent the penetration and thus to overcome this degradation process [1].

The ability that a pre-mixed one-coat render has to

Cooresponding author: Inês Flores-Colen, Ph.D., associate professor, research fields: pathology, diagnosis, maintenance and durability. resist the penetration of water is expressed by the coefficient of water absorption by capillarity, which measures the rate at which the material absorbs water by this mechanism. The requirements for resistance to water penetration are defined in EN 998-1:2010 in three classes, namely:

- W0 when not specified;

- W1 when the value is between 0.2 and 0.4 $\mathrm{kg} / \mathrm{m}^{2} \cdot \min ^{1 / 2}$

- W2 when the value appears less than 0.2 $\mathrm{kg} / \mathrm{m}^{2} \cdot \min ^{1 / 2}$.

For durability testing, the same standard recommends for one coat mortars the study of adhesion, and also the water permeability after exposure to climate cycles with a maximum 
requirement of $1 \mathrm{ml} / \mathrm{cm}^{2}$, after $48 \mathrm{~h}$ of testing [2]. However, as mentioned by Quintela [3], these tests may not correspond to significant variations that can express changes in terms of real in-service performance.

As regards ETICS (external thermal insulation composite systems), the ability of these systems to confer water resistance is expressed by water absorption coefficient determined by capillarity which should be less than $1 \mathrm{~kg} / \mathrm{m}^{2}$ after $1 \mathrm{~h}$. If this value is less than $0.5 \mathrm{~kg} / \mathrm{m}^{2}$ after $24 \mathrm{~h}$, the performance is considered better and includes resistance to freeze-thaw [4].

To ensure the minimum requirements recommended by the EOTA (European Organization for Technical Approvals) 2000 standards, mortars are formulated with hydrophobic agents in order to decrease the surface tension between the solid and the water, leading to an increased contact angle between the two surfaces. For one one-coat mineral renders, metallic soaps such as salts of oleic or stearic acid are commonly used to provide hydrophobicity to renders due to their efficiency/cost ratio. In this context, any mortar which incorporates concentrations of $0.2 \mathrm{w} / \mathrm{w} \%$ to $0.5 \mathrm{w} / \mathrm{w} \%$ of these compounds will show coefficients of water absorption by capillarity well below the maximum levels adopted by standard requirements [2]. On the other hand, during the last decade, silanes have been introduced as well. Silanes are silicon based chemicals that have a hydrolytically sensitive centre which can react with inorganic substrates to form stable covalent bonds and an organic moiety that alters the surface properties of treated surfaces $[5,6]$. Therefore, they are used to modify the surface energy or wettability of substrates. Indeed, Wacker, et al have recently shown that silanes improve the hydrophobic behaviour of mortars, yielding better water resistance and longer effect $[6,7]$.

Although it is generally accepted that higher durability are associated with low water absorption coefficients, for longer periods, other factors seem to play a role. In fact, field observations of façades indicate signs such as dirt deposition, discolouration, among others which is thought to be associated with the degradation or leaching of water repellent agents after the first years. This has been evidenced by the higher wettability of façades, indicating a reduction of contact angle associated with the increase of surface tension of the solid. Moreover, studies involving long-term durability of concrete and mortars containing silanes and siloxanes have demonstrated the need for additional care regarding drying conditions and application, as well as the use of higher concentrations and optimised mortar formulations depending on the chemical nature. Yet, further research studies in this field are still needed [8].

Previously reported data upon 6 years of monitoring water absorption coefficient and water absorption determined by the Karsten tube method, revealed changes in the ability of the one-coat render to resist to the penetration of liquid water, proving that the durability of this protective coat is limited and aesthetic degradation is progressive [9].

In order to get a better understanding of the durability of these renders including the identification of the mechanisms responsible for the reduction of their efficiency over time, in this paper, the performance of a coloured one-coat render and two ETICS when exposed to in-service degradation agents are assessed in terms of resistance to liquid water penetration and the role of hydrophobic agents analyzed. As regards the one coat render, this paper represents a large time span analysis, with a global time exposure to environmental conditions up to 10 years using several premixed one-coat rendered walls with and during 4 and 6 years after construction in the case of ETICS.

\section{Experimental Campaign}

2.1 Monitorization of Rendered Walls Exposed to Natural External Conditions (Semi-laboratorial Tests)

The experimental work consisted in the application 
of one-coat render containing salts of stearic acid and oleic hydrophobic agents classified as W2 by EN 998:1 [10], using a machine for discontinuous projection on masonry walls (brick $11 \mathrm{~cm}$ ). Four different orientations for exposure have been considered: north, south, east and west. For a preliminary evaluation of mortar roughness on the surface wettability, the façade exposed to north was also submitted to a different finish, i.e., float finish (also known as sanded) unlike all other cases where a scraped finish was applied. Table 1 summarized the experimental conditions used.

Upon application, the one-coat renders were inspected regularly each year. These inspections included: (1) perpendicular tensile tests (pull-off tests) to evaluate adherence; and (2) render inherent capacity to resist to liquid water penetration.

After the pull-off test, samples were collected from the rendered walls and prepared with $4 \times 4 \mathrm{~cm}^{2}$ with thickness according to the nature of the rupture of the mortar but always higher than $1 \mathrm{~cm}$; Absorption coefficient of water by capillarity was also determined for the collected samples, according to EN 1015: 18 [11] (Fig .1a).
Samples from the pull-off tests were also tested for the determination of open porosity by hydrostatic weighing method with immersion in water, in order to investigate possible changes in the internal structure of mortars which may, by changing the structure of pores, contribute to possible variations of capillarity and water absorption [12].

Penetration tests of liquid water under pressure, known as pipe method or Karsten test, were conducted on tested-walls; This technique consists in measuring the volume of water absorbed by the mortar's surface in a given section and for an established period of time. The procedure involves the use of a graduated tube, pipe-shaped, with a $5.7-\mathrm{cm}^{2}$ circular cross-section along the surface contact with mortar (Fig. 1b); The total height of the water column applied is $9 \mathrm{~cm}$ which is ensured by regularly refilling of the tube every $10 \mathrm{~min}$. The results for this analysis are expressed in terms of accumulated values of absorbed water after $180 \mathrm{~min}$.

\subsection{Monitorization of ETICS Exposed to Natural External Conditions (Semi-laboratorial Tests)}

The experimental work consisted in the application

Table 1 Relationship between orientations of the rendered walls and parameters of the study.

\begin{tabular}{lll}
\hline Wall orientation & Color & Finishing \\
\hline North & Red ("brick") & Float finish/sanded \\
South & Red ("brick") & Scraped \\
East & Red ("brick") & Scraped \\
West & Red ("brick") & Scraped \\
\hline
\end{tabular}

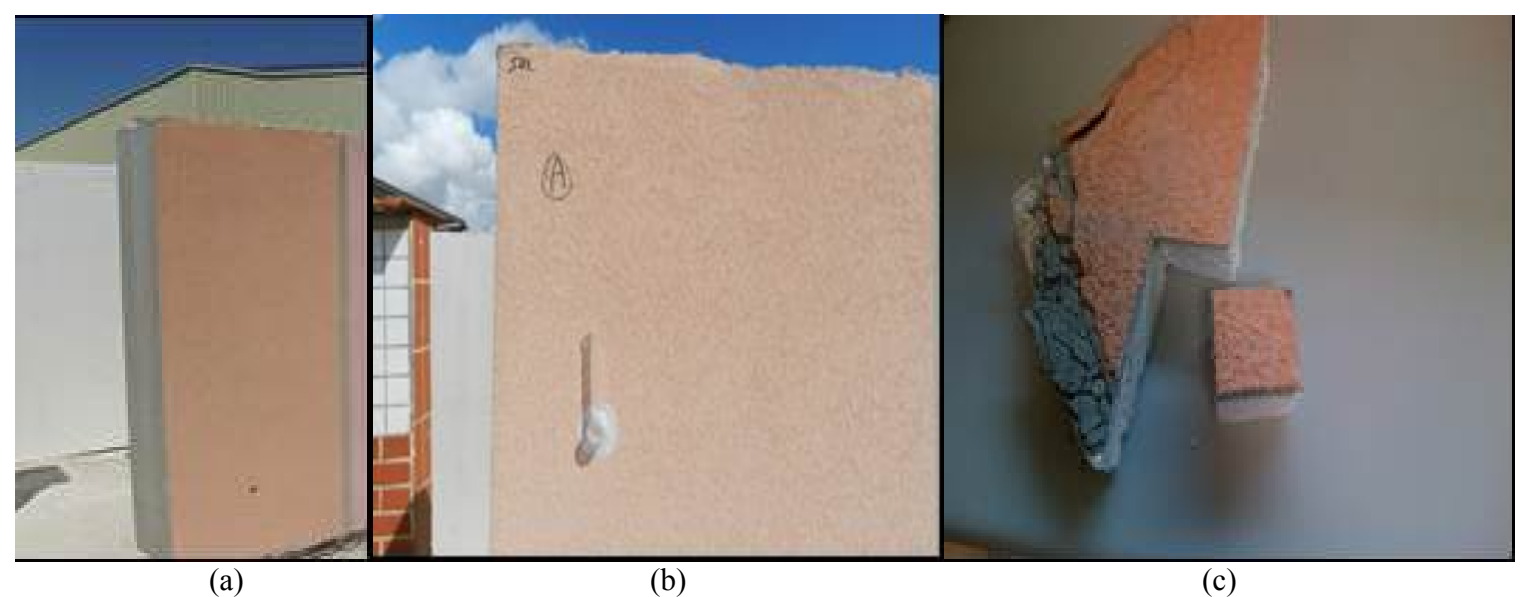

Fig. 1 The experiment: (a) ETICS samples preparation; (b) Karsten tube test; (c) extracted sample for the determination of the coefficient of absorption of water by capillarity. 
Table 2 Relationship between orientations of the ETICS wall and parameters of the study.

\begin{tabular}{ll}
\hline Wall orientation & Color \\
\hline North & Red ("brick") \\
South & Red ("brick") \\
\hline
\end{tabular}

of ETICS system using an organic render and silane agents as hydrophobic agents. Only two different orientations for exposure have been considered: north and south. Table 2 summarizes the experimental conditions used.

Upon 4 years in-service, the ETICS walls' water resistance capacity was evaluated using the: (1) Karsten pipe test method; and (2) capillarity tests.

Karsten test, were conducted on tested-walls considering same methodology as before (Fig. 1b);

Samples were collected from the rendered walls (Fig. 1c) and prepared with $4 \times 4 \mathrm{~cm}^{2}$ (thickness equals to the sum of the insulation EPS (expanded polystyrene) plus the basecoat and the organic finishing render). The absorption coefficient of water by capillarity was according to ETAG 004 [4].

\subsection{In Situ Evaluation of ETICS Exposed to Natural External Conditions}

For the in situ evaluation of ETICS, a system with the corresponding ETA (European Technical Assessment) 11/0287 [13] that includes a finishing render containing polyethene waxes as hydrophobic agent was studied.

Visual inspections were carried out over time starting in 2008 up to 2014 (i.e., 6 years' exposure conditions) in order to evaluate aesthetical performance in all orientations.

\section{Results}

3.1 Monitorization of Rendered Walls Exposed to Natural External Conditions (Semi-laboratorial Tests)

The results for the water absorption determined by capillarity tests and water absorption determined using the Karsten tube after 10 years of exposure to environmental conditions, are summarized in Table 3 and Fig. 2. For comparison data collected in the laboratory, they are also presented in Table 3 and Fig. 2.

In order to assess the effect of internal structural changes resulting from the dynamics of hydration of cement of mortar over time on the mortars, the porosity of samples collected from pull-off testes over 10 year was determined. Fig. 3 shows the adhesion (pull-off test) and open porosity values for samples collected from the various walls' orientations.

\subsection{Monitorization of ETICS Exposed to Natural External Conditions}

Table 4 shows the absorption of water coefficients determined by capillarity (according to ETAG 004 [4]) and water absorption after $180 \mathrm{~min}$ for various walls' orientations using the Karsten tube method, after 4 years of exposure to environmental conditions of the ETICS system under semi-laboratorial conditions.

Table 3 Results of the coefficient of absorption of water by capillarity and water absorption after 180 min for various walls' orientations, after 10 years of exposure to environmental conditions.

\begin{tabular}{|l|l|l|l|l|}
\hline \multirow{2}{*}{$\begin{array}{l}\text { Façade } \\
\text { orientation }\end{array}$} & \multicolumn{2}{|c|}{$C\left(\mathrm{~kg} / \mathrm{m}^{2} \cdot \mathrm{min}^{1 / 2}\right)$} & \multicolumn{2}{|c|}{ Absorption of water under pressure* $(\mathrm{ml})$} \\
North & Lab & 10 years & \multirow{3}{*}{$<0.5$} & 0.20 \\
\hline South & 0.030 & & 5.60 \\
\hline East & 0.033 & 0.019 & 0.80 \\
\hline West & & 0.046 & 8.50 \\
\hline
\end{tabular}

*Accumulated value over $180 \mathrm{~min}$. 


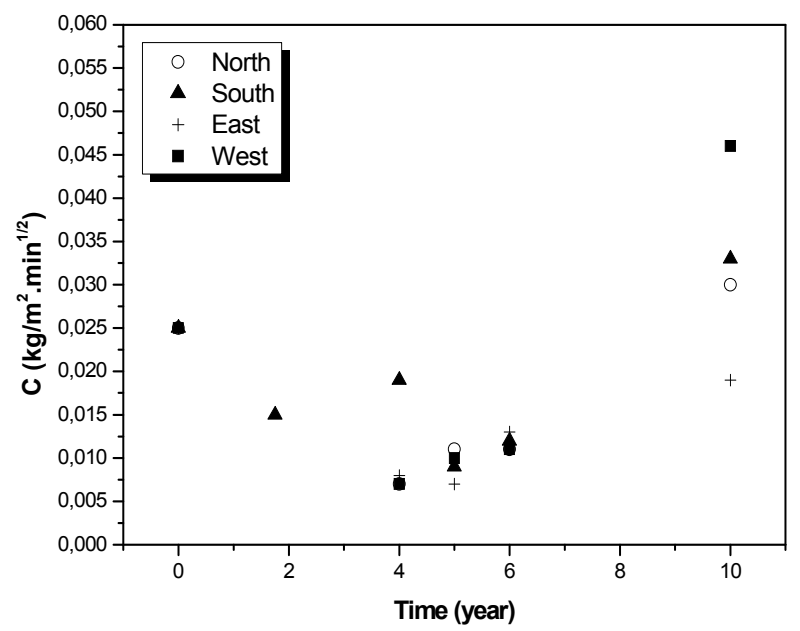

(a)

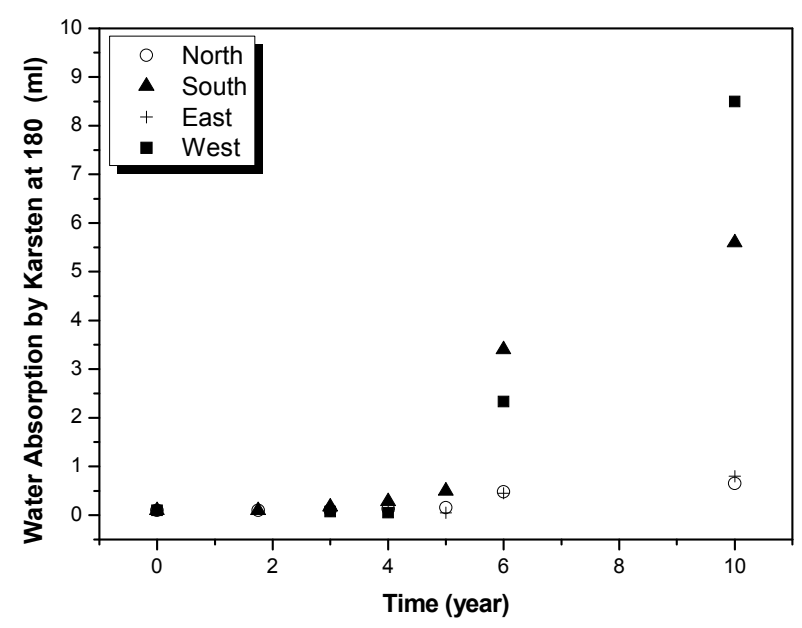

(b)

Fig. 2 Results for rendered wall after 10 years of different exposure conditions as a function of time for: (a) capillarity coefficient; and (b) water absorption by Karsten tube.

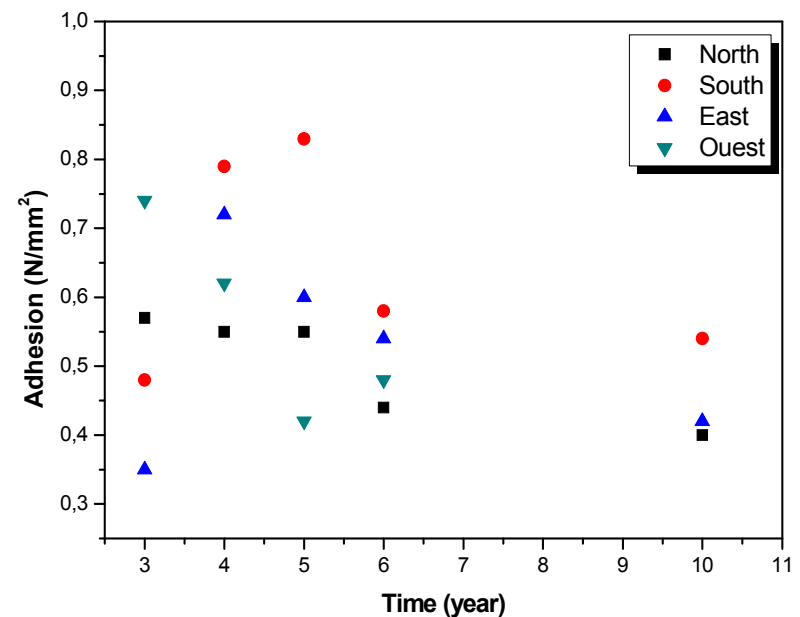

(a)

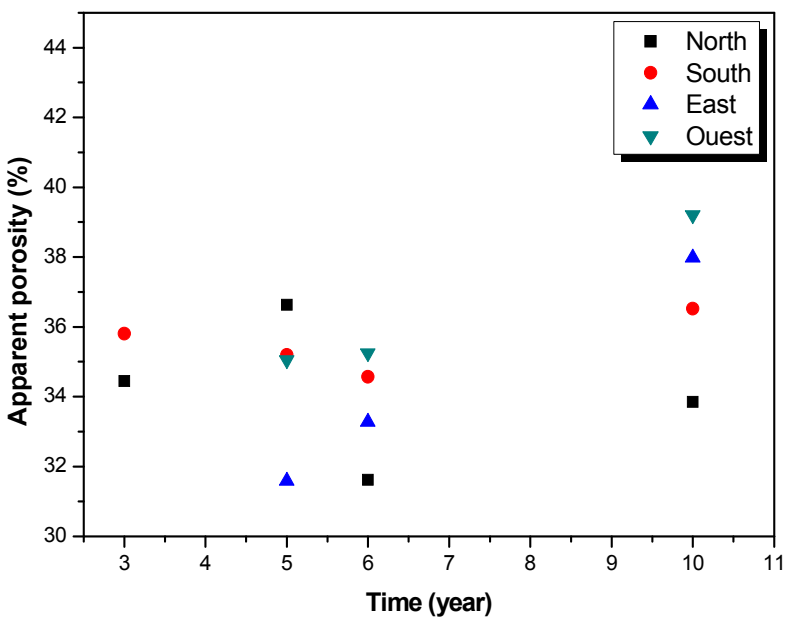

(b)

Fig. 3 Variation of the: (a) pull-off adhesion test; and (b) open porosity for the one coat rendered walls orientations as a function of the time.

Table 4 Results of the coefficient of absorption of water by capillarity and water absorption after 180 min for various ETICS walls' orientations, after 4 years of exposure to environmental conditions.

\begin{tabular}{|c|c|c|c|c|c|c|}
\hline \multirow{3}{*}{$\begin{array}{l}\text { Façade } \\
\text { orientation }\end{array}$} & \multicolumn{4}{|c|}{ Water absorption by capillarity $\left(\mathrm{kg} / \mathrm{m}^{2}\right)$} & \multirow{2}{*}{\multicolumn{2}{|c|}{ Absorption of water under pressure* $(\mathrm{ml})$}} \\
\hline & \multicolumn{2}{|c|}{ After $1 \mathrm{~h}$} & \multicolumn{2}{|c|}{ After $24 \mathrm{~h}$} & & \\
\hline & $\mathrm{Lab}$ & 4 years & Lab & 4 years & $\mathrm{Lab}$ & 4 years \\
\hline North (A) & & $<0.01$ & & $<0.01$ & & 0.10 \\
\hline North (B) & 0.05 & - & 0.22 & - & $<0.5$ & 0.10 \\
\hline South (A) & & $<0.01$ & & $<0.01$ & & 0.20 \\
\hline
\end{tabular}

*Accumulated value over $180 \mathrm{~min}$.

\subsection{In Situ Evaluation of ETICS Exposed to Natural} External Conditions

Fig. 4 presents the aesthetical evolution of the in situ evaluation of ETICS considering south and west orientations at the beginning and after 4 and 6 years of exposure conditions. For the remaining orientations, no data are presented since they still do not reveal considerable anomalies. 


\section{Discussion}

Upon application, the one-coat renders were inspected regularly each year. As expected, the results presented in Fig. 2 and Table 3 show differences in the absorption coefficient of water by capillarity for the various walls' orientations studied, after 10 years of exposure to environmental conditions. Interestingly, after 6 years the water absorption determined using either method shows a significant increase, confirming the expected result previously outlined [9]. Something Also interesting was the fact that the Karsten pipe method is more sensitive than the capillarity tests as it allowed early and unequivocal identification of the effect of orientation and exposure time. Thus, this method has been used to study the impact of orientation on façade water resistance.

Analyses of Table 3 and Fig. 2 show that south and west orientations have less resistance to water penetration as water absorption values are substantially higher for these orientations.
Furthermore, this difference increases with time with the "rupture point" occurring around 5 to 6 years, suggesting that maintenance repairs should be scheduled for this period.

As regards the role of the internal structural changes resulting from the dynamics of hydration of cement of mortar over time on the mortars, from Fig. 3 it is clear that the data are rather scattered. Even though it may be acceptable to consider that adhesion seems to decrease over time while the porosity slightly increases, no clear trend can be established as most of the differences are within the method's error variations. These results indicate that the key parameter affecting water resistance penetrance is the hydrophobicity of the render.

Concerning the semi-laboratorial evaluation of the ETICS walls water resistance capacity, the results presented in Table 4 show that upon 4 years there is hardly any significant effects. On the other hand, no damages in aesthetical performance were noticed in an

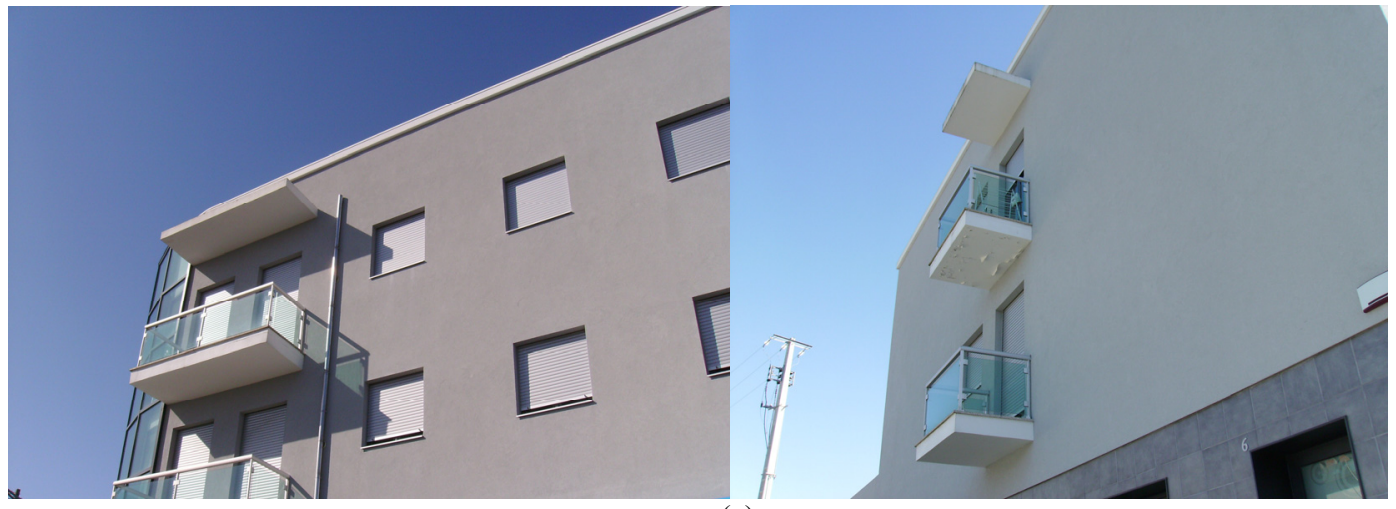

(a)

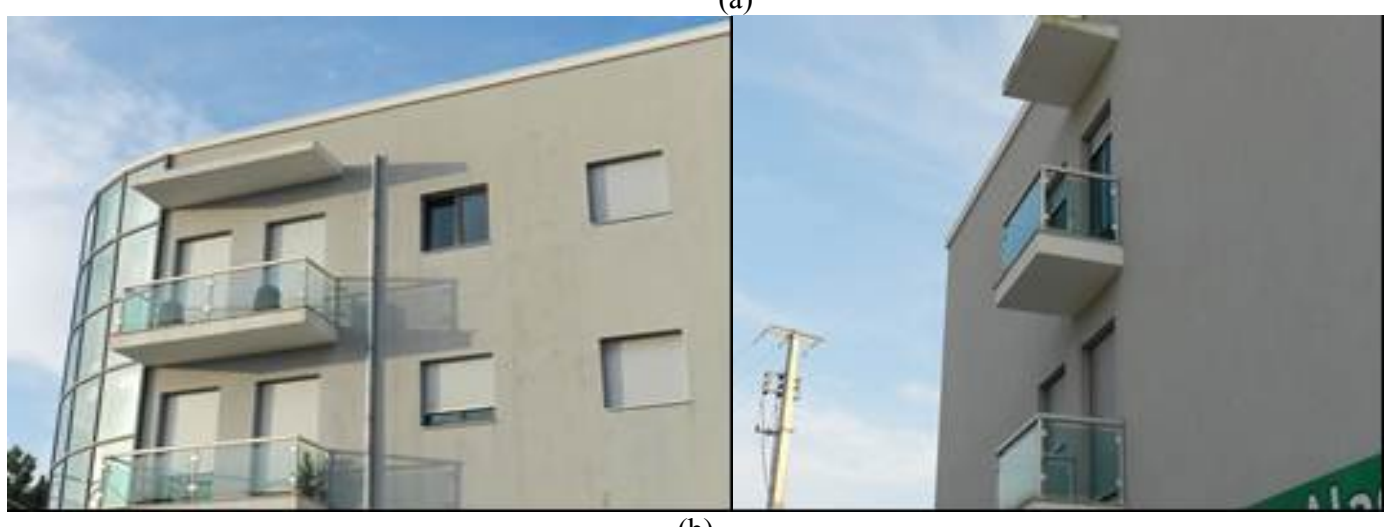

(b)

Fig. 4 Visual inspection of in situ evaluation of ETICS: (a) beginning and after 4 years; (b) 6 years exposure conditions (left: south orientation; right: north orientation). 
in situ evaluation of ETICS exposed to natural external conditions for up to 4 years as shown in Fig. 4. However, between the 5 th and 6 th year, visible dark and green spots are clearly visible especially for the south orientation. This is thought to be associated with fungi and algae, as a result of a potential water penetration on the surface of finishing thin render of the system.

Although water absorption was recorded for all cases, all of them are below standard limits. Hence, it is more than reasonable to consider degradation as a process mainly at their surface responsible for the aesthetical ageing. On the other hand, considering that water absorption is more intense for the south and west orientations, especially when the Karsten method is used, it seems that other degradation mechanism, besides leaching, may be involved such as photochemical and thermal degradation. Additionally, other processes can be associated with façade ageing, namely water evaporation as water vapour resistance and dry index are complementary properties to be considered. Furthermore, leaching of other components such as biocides, also contributes to the façade ageing especially in organic renders and coatings as those used in ETICS.

\section{Conclusions}

Field testing, such as the determination of the coefficient of absorption of water by capillarity and Karsten tube, revealed behavior changes in the ability of façades systems, as one coat renders or ETICS, to resist to the penetration of liquid water.

Despite considering their ability to resist to water penetrance, since both solutions present values below recommend limits by the respective standards, it is reasonable to assume that situations more exposed to climatic conditions begin a process of degradation between 5 and 6 years of service. This degradation is expressed by grey and green spots presenting potential fungi and/or algae colognes. Originally, that spots are just sporadic but they increase with time.

Since materials still resist to water penetrance, it is reasonable to consider that the degradation is mainly at their surface; On the other hand, the fast increase of capillarity and Karsten values of water permeability for south and west orientations, indicate that degradation mechanisms cannot be associated exclusively with leaching of the hydrophobic agents. Instead, additional processes such as photochemical and thermal degradation may also be involved. Future works should focus also on this hypothesis in order to improve durability. Finally, it is important to considerer the relevance of the Karsten pipe methodology since it is the one that reflects better changes on ability of façades solutions to water resistance, and presents better correlation with aesthetical ageing as a result of exposure to real conditions.

\section{Acknowledgments}

This work was developed in the scope of the project CICECO-Aveiro Institute of Materials, financed by national funds through the FCT/MEC and when applicable co-financed by FEDER under the PT2020 Partnership Agreement. The authors acknowledge also the support of the CERIS/ICIST research centre from IST and of FCT (Foundation for Science and Technology).

\section{References}

[1] ANFAPA (Asociación Nacional de Fabricantes de Morteros Industrials) and ITeC (Instituto de Tecnologia de la Construcción de Cataluna). 2008. "Morteros Monocapa. Revestimientos de Fachada." ANFAPA and IteC. Acessed on October 5 2015. http://www.anfapa.com/downloads/46_monografia-morte ros--monocapa-ok.pdf. (in Portuguese)

[2] CEN (European Standards Organization). 2010. CEN-EN 998-1: Specification for Mortar for Masonry. Rendering and Plastering Mortar. Brussels: Committee for Standardization.

[3] Quintela, M. A. 2006. "Durabilidade de Revestimentos Exteriores de Parede em Reboco Monocamada." M.Sc. thesis, FEUP (Faculdade de Engenharia da Universidade 
do Porto). (in Portuguese)

[4] European Organization for Technical Approvals. 2008. Guideline for European Technical Approval of External Thermal Insulation Composite Systems with Rendering. Brussels: European Organization for Technical Approvals.

[5] Tanford, C. 1980. The Hydrophobic Effect. New York: Wiley.

[6] WACKER. 2014. "The Threat: What Is Just Rain to Most People Is the Worst Enemy for Coatings." WACKER. Accessed on September 29, 2014. http://www.wacker.com/cms/media/publications/downloa ds/6928_EN.pdf.

[7] Lanzón, M., and Garcia-Ruiz, P. A. 2008. "Effectiveness and Durability Evaluation of Rendering Mortars Made with Metallic Soaps and Powdered Silicone." Construction and Building Materials 22: 2308-15.

[8] Raupach, M., and Wolff, L. 2005. Long Term Durability of Hydrophobic Treatment on Concrete. Aachen: Institute for Building Materials Research of the Technical University.
[9] Silva, L., Flores-Colen, I., Vieira, N., and Timmons, A. B. 2011. "Natural Ageing Tests to Study In-service Water Resistance of Pre-mixed One-Coat Rendered Walls with Hydrophobic Agents." In Proceedings of XII DBMC (Durability of Building Materials and Components), 1-9.

[10] LNEC (Laboratório Nacional de Engenharia Civil). 2004. Relatório 427/05: Homologação do Revestimento de Paredes Monocamada, Weber.Pral Classic. Lisboa: LNEC. (in Portuguese)

[11] CEN. 2002. CEN-1015:18: Methods of Test for Mortar for Masonry-Part 18: Determination of Water Absorption Coefficient Due to Capillary Action of Hardened Mortar. Brussels: Committee for Standardization.

[12] Flores-Colen, I., Silva, L., De Brito, J., and De Freitas, V. 2010. "In-service Parameters from Façade Rendering Mortars: Bulk Density and Open Porosity Determined from Samples Collected in Situ." Structural Survey 28 (1): 17-27.

[13] LNEC. 2011. European Technical Approval, ETA 11/0287: Weber.Therm Classic. Lisboa: LNEC. 